\title{
Investigation of Graduate Student Stress in Speech Language Pathology
}

Rochel Lieberman

University of Cincinnati, lieberrl@mail.uc.edu

Lesley Raisor-Becker

University of Cincinnati, raisorlj@ucmail.uc.edu

Carney Sotto

University of Cincinnati, sottocd@ucmail.uc.edu

See next page for additional authors

DOI: doi.org/10.30707/TLCSD2.2Lieberman

Follow this and additional works at: https://ir.library.illinoisstate.edu/tlcsd

Part of the Communication Commons, and the Other Social and Behavioral Sciences Commons

\section{Recommended Citation}

Lieberman, Rochel; Raisor-Becker, Lesley; Sotto, Carney; and Redle, Erin (2018) "Investigation of Graduate Student Stress in Speech Language Pathology," Teaching and Learning in Communication Sciences \& Disorders: Vol. 2: Iss. 2, Article 6. DOI: doi.org/10.30707/TLCSD2.2Lieberman

Available at: https://ir.library.illinoisstate.edu/tlcsd/vol2/iss2/6

This Student Voices is brought to you for free and open access by ISU ReD: Research and eData. It has been accepted for inclusion in Teaching and Learning in Communication Sciences \& Disorders by an authorized editor of ISU ReD: Research and eData. For more information, please contact ISUReD@ilstu.edu. 


\title{
Investigation of Graduate Student Stress in Speech Language Pathology
}

\begin{abstract}
The purpose of this research was to investigate the average stress levels and types of stressors experienced by graduate students (GS) in speech-language pathology (SLP) programs and the academic supports GS perceived to be helpful. An online survey examining stress was administered to $238 \mathrm{GS}$ in SLP. The average stress level, types of stressors, demographic characteristics of participants related to their stress response, and reported academic program supports were analyzed. Correlation coefficients were computed to determine the relationship between reported stress, demographic variables, and program characteristics. Moderate and high levels of stress were reported by $96 \%$ of SLP GS as measured by the Academic Stress Scale. Lower levels of reported total stress were correlated with increased age, enrollment in a distance learning program, and being married or living with a partner. Participants most commonly mentioned frequent communication with faculty and access to on campus stress resources/education about stress management to be helpful. The results suggest that the majority of GS in SLP bear moderate and high levels of stress. Future research is warranted to investigate ways that faculty and student communication skills and academic supports can be implemented to aid in stress management.
\end{abstract}

Keywords

Graduate Student Stress, SLP, Speech Language Pathology Students

Authors

Rochel Lieberman, Lesley Raisor-Becker, Carney Sotto, and Erin Redle 
As training institutions across the country recognize the importance of mentally and physically healthy students, there is a growing appreciation of the stress students experience when being trained in health care disciplines (Moffat, McConnachie, Ross \& Morrison, 2004). Researchers have documented the stress and psychiatric symptoms secondary to counterproductive stress in medical and nursing students (Adsett, 1968; Mese \& Spano, 1989). Allied health academic programs are recognizing similar stress effects in their students (Landow, 2006). Graduate students (GS) in speech-language pathology (SLP) are under pressure to meet their academic program demands (Beck \& Verticcho, 2014). An intense academic workload, test-taking fears, practicum requirements, and the financial burden of being in graduate school (Hyun, Quinn, Madon, \& Lustig, 2006) may add to SLP GS stress. Due to the detrimental effects of chronic stress on a person's health and well-being, many allied health and SLP programs are supporting students in managing their stress to help them become academically and professionally successful (Beck \& Verticcho, 2014; Beck, Seeman, Verticcho \& Rice, 2015; Beck, Verticchio, Seeman, Milliken, \& Schaab, 2017). Thus, the present study aimed to investigate SLP GS stress levels, the types of stressors experienced, and academic supports suggested as potentially helpful.

\section{Understanding Student Stress}

Students, as a whole, are particularly susceptible to stress (Calkins, Arnold, \& Willoughby, 1994; McLaughlin, 1985), plausibly due to the transitional nature of college life (Towbes \& Cohen, 1996), adjustment to a new social environment, pressure to maintain a high level of academic achievement (Ross, Niebling, \& Heckert, 1999), and financial strain (Hyun et al., 2006). When students enter an advanced program, they may find less coursework guidance, requiring selfmotivation (Hyun et al., 2006; Peters, 1997). For instance, according to the Cooperative Institutional Research Program (CIRP) Freshman Survey, UCLA's annual survey of the nation's entering students at four-year colleges and universities, first-year college students' self-ratings of their emotional health dropped to record low levels in 2010 (Pryor, Hurtado, DeAngelo, Palucki, \& Tran, 2010).

As students continue into advanced academic programs, such as graduate school, stress may be more intensified with amplified financial worries, while academic support and guidance is received less than for their undergraduate counterparts (Hyun et al., 2006). Graduate students may have additional stressors of conducting research, teaching, and publishing, which may result in increased thoughts about leaving the graduate program (Hyun et al., 2006). To this end, Kohn and Frazer (1986) argued that GS experience pressure for academic and clinical performance, along with stress related to excessive homework, ambiguous assignments, and uncomfortable classroom environments.

Allied health programs may have unique stressors as they require continuous evaluation (exams, papers, and clinical feedback sessions) of students and may intensify already elevated stress levels (American Speech-Language-Hearing Association [ASHA], 2016; Crary, 2013; Hamaideh \& Hamdan-Mansour, 2014). A significant number of medical students experienced psychological distress, associated with increases in years in the program, work and required study hours. Their stress is intensified with low social support and reduced emotional resilience (Bore, Kelly, \& Nair, 2016). Similarly, nursing students reported increased levels of perceived stress as they advance in

their programs (Papazisis, Tsiga, Papanikolaou, Vlasiadis \& Sapountzi-Krepia, 2008) and 
described their academic coursework, above all else, as the most stressful. Rooted in these areas are reports about relationships, parenthood, time management, illness, travel and work pressures to be compounding sources of stress (Lo, 2002). Aside from academic demands, nursing students report physical demands that contribute to back pain, stress related symptoms, and indications of work-life imbalance such as fatigue and poor eating (Crary, 2013).

Graduate Student Stress in SLP. Unlike the stress that professional programs such as law, medicine, and physical therapy place on their students (Hyun et al., 2006; Walsh, Feeney, Hussey, \& Donnellan, 2010), stress experienced by GS in the field of SLP has not been extensively studied (Beck \& Verticcho, 2014; Beck et al., 2015; Beck et al., 2017. GS in SLP balance a heavy course load along with their life obligations (typically including work and home responsibilities). The scope of practice in SLP (e.g. dysphagia and literacy) and resulting required coursework content areas and clinical experiences has grown in recent years (ASHA, 2016). ASHA(2016) requires that GS must have opportunities to acquire the full range of knowledge and skills to practice in all types of clinical settings. Thus, students are required to demonstrate knowledge about research methods and the integration of research principles into clinical practice, many programs in SLP also require that GS assist in research projects along with difficult course work and high clinical expectations for their practicum experiences (ASHA, 2016).

Graduate Student Stress and Academic Institutions. Although the quandary of GS stress is not new, many academic institutions are noting an increase in the number of student referrals for mental health counseling associated with the stress/anxiety students experience during their training (Center for Collegiate Mental Health, 2014). While this increase may be related to positive changes in increased identification of mental health disorders and awareness of the importance of seeking help among students (rather than actual increases in prevalence/severity of mental health problems), many students are experiencing mental health difficulties that are impacting their abilities to cope. If left untreated, mental illness may significantly impact a student's academic success, productivity, substance use/abuse, and social relationships (Hunt \& Eisenberg, 2010).

Consequently, researchers have found that stress in GS presents a real conundrum for universities, especially considering the push in academia for increased student retention and higher graduation rates. Despite the pressure to retain students, it has been well-documented that student stress may lead to untreated mental health problems and is a significant factor in graduate student dropout rates (Turner \& Berry, 2000; Wilson, Mason, \& Ewing, 1997). Given these arguments, there are factors associated with successful graduate programs (those reporting a high level of student emotional well-being and retention), and many graduate schools are adopting these programmatic characteristics to be an additional goal for their academic units. For example, providing students with a higher level of social, administrative, and financial support has been associated with reported lower stress levels among students (Benton, Robertson, Wen-Chih, Newton, \& Benton, 2003). Also, increased mentoring and supervision along with easy access to mental health counseling services are related to happier GS (Benton et al., 2003). Finally, some universities are being proactive in how they approach student stress reduction/management by facilitating stress reduction groups. The creation of these groups is rooted in the understanding of the importance of self-care and the accumulating scientific evidence on how physiology may be affected by techniques which use the mind, including meditation, biofeedback, and guided imagery (Gordan, 2014). Particularly for Communication Sciences and Disorders (CSD) GS, partaking in yoga 
classes (Beck \& Verticcho, 2014; Beck et al., 2015) and mindfulness training (Beck et al., 2017) has been found to lower perceived stress levels (Beck \& Verticcho, 2014; Beck et al., 2015). While several universities are placing their students' well-being at the center of their academic programs, there is wide variation in the types of support offered to students across universities (Beck \& Verticcho, 2014; Beck et al., 2015; Beck et al., 2017; Deckro, Ballinger, Hoyt, Wilcher, Dusek, Myers, Greenberg, Rosental, \& Benson, 2002; Gordan, 2014; Hyun et al., 2006; Mese \& Spano, 1989). Despite anecdotal faculty notations of severe student stress, systematic research examining student stress in SLP academic programs is lacking.

Generational Differences in Stress. While there are individual differences in the interpretation of and response to stressful events (Ellis, Jackson, \& Boyce, 2006), there are also general and observable patterns with age as a potential factor. In the Stress in America survey conducted by the American Psychological Association (APA) in 2011, Millennials (born after 1982) and Gen Xers (born between 1965-1981) reported higher stress levels compared with the Baby Boomer (born between 1946-1964) and Mature (born between 1927-1945) generations (American Psychological Association [APA], 2011). Most current college and GS were born after 1980 and fall into the Millennial Generation, also known as generation Y. This generation presents with the positive traits of increased achievement, teamwork, and modesty and the negative traits of being over scheduled, over monitored, and over-pressured (Bland, Melton, Welle, \& Bigham, 2012). While young millennials may have more resilience, they may be lacking in problem solving and patience, which can reduce stress tolerance and impact their ability to cope with stress in college (Bland et al., 2012). In addition, due to the rising cost of living expenses and tuition, an overwhelming majority $(80 \%)$ of millennial undergraduate and GS work while taking heavy course loads (Riggert, Boyle, Petrosko, Ash, \& Rude-Parkins, 2006). While there is research to support that employment can increase academic commitment and efficiency and decrease alcohol consumption, employment may also be a threat to academic achievement and create additional stress for the millennial student as he/she is forced to manage work and school obligations (Butler, Dodge, \& Faurote, 2010; Riggert et al., 2006).

Stress and Gender. Gender may also influence how an individual responds to stress. The biological responses to stress and anxiety are different between males and females (Bangasser \& Wicks, 2017; Kilpatrick et al., 2015; Seo, Ahluwalia, Potenza, \& Sinha, 2017) with evidence supporting physiological differences contributing to observed differences between genders (Donner \& Lowry, 2013; Marques et al., 2016; Ngun, Ghahramani, Sánchez, Bocklandt, \& Vilain, 2011). As college freshman, females report higher levels of stress compared to male counterparts (Garett, Liu, \& Young, 2017), with this pattern continuing through adulthood (Matud, 2004). Working mothers, regardless of marital status, face higher stress levels and an increase in stress related health conditions (Anthony et al., 2005; Giuseffi et al., 2011).

In summary, stress is detrimental and anecdotally noted in SLP academic programs, requiring a systematic investigation. The purpose of this study was to investigate the average stress levels and types of stressors experienced by GS in SLP. Additionally, this study aimed to identify academic supports that GS in SLP perceive as helpful. Specifically, this study addressed the following four research questions:

1. What is the stress level of GS in SLP as measured by the Academic Stress Scale overall stress score? 
2. What types of stressors do GS in SLP rate as eliciting "extreme stress," "moderate stress," "hardly stressed," "no stress"?

3. What demographic and program characteristics are related to the overall stress score of SLP GS measured by the Academic Stress Scale?

4. What type of academic program supports do SLP GS report as being helpful?

\section{Methods}

General Stress Survey. A 28 question survey was developed by the authors to document the stress levels and types of stressors that SLP GS experience. The survey was designed to measure multiple aspects of stress in GS; however, only the relevant portions that relate to the current research questions will be discussed. The additional areas queried are for a separate larger investigation. Specifically, the survey included six sections that measured academic stress, coping mechanisms through the Brief COPE (Carver, 1997), the number of hours spent completing a variety of academic activities, demographic information, open-ended questions regarding suggestions about how academic programs could support students with their stress levels, and self-talk during a stressful event. Only portions of the survey results that directly relate to the specific questions of the current research will be discussed in this article (academic stress, demographic questions, and open-ended questions regarding suggestions about potential student supports).

Academic Stress Scale, Information about Participants, and Suggested Program Supports. Stress is typically assessed by instruments that rely upon individuals reporting their perceptions of psychological stress. Although there are many stress surveys available, the Academic Stress Scale was chosen because it offered a concise and specific method of measuring academic stress in students. The Academic Stress Scale has also been used with success in capturing the stress experienced by students in other research (Flanning, 2016; Smith \& Renk, 2007; Wilks, 2008). This instrument reports high reliability, meaning that the items students rate as stressful are likely to remain sources of stress even if the survey is taken at different measurement times (i.e. before finals or at the beginning of the semester) (Kohn \& Frazer, 1986). The Academic Stress Scale was included in the survey as one question with 26 Likert scale prompts (5 levels) that targeted students' current stressors. This section of the survey asked participants to rate factors, such as grades, papers, tuition cost, and unclear assignments as contributing to their stress by selecting: N/A, No Stress, Hardly Stressed, Moderately Stressed, or Extremely Stressed.

In addition to responding to the Academic Stress Scale, participants were asked to report information about themselves and their program. Data regarding participants' age, race, marital status, presence of children, and current program status (full-time vs. part-time, cohort size, etc.) were collected. In addition, participants answered questions about their frequency of exercise, advisor meetings, and if they had been referred for mental health services (including medication for depression and/or anxiety). If they answered positively, they were asked if these referrals took place prior to enrollment in graduate school or during their graduate program. Finally, participants were asked to describe the stress/mental health services offered at their university along with suggestions that they have for universities to help students manage stress during graduate school.

Data Collection. The Institutional Review Board (IRB) approved the research and the survey was uploaded to a widely used survey platform (https://www.surveymonkey.com/). A link to the 
electronic survey was shared through an email to graduate program faculty members and through the social media outlet of Facebook (local National Student Speech-Language-Hearing Association chapter's Facebook page). The survey link was shared extensively by students on SLP graduate student Facebook groups across the country (one Facebook share resulted in over 200 responses representing all geographical regions in the US). The survey was open for six months (December-May), and 238 Master's level students studying SLP from 85 universities from across the United States, Canada, and Australia responded. In the United States, all geographical regions were represented. Only single academic programs were represented in Canada and Australia. A response rate could not be calculated due to the snowball sampling procedure.

Data Analysis. Data obtained from the Academic Stress Scale were entered into SPSS Version 24.0 (IBM Corp., 2016). For the specific stress response items, the individual Likert-style question responses were assigned a numerical value with lower scores reflecting low stress and higher scores reflecting more stress. A total score was found by summing the individual item scores. These total scores were further coded into ranges of stress including: low (score range: $0-30$ ), moderate (score range: $30-50$ ) and high (score range: $50-80$ ). Descriptive statistics, such as frequency counts were calculated for demographic and program variables.

Correlation coefficients were computed to determine if there was a relationship between the total stress score as measured by the Academic Stress Scale and the following variables: credit hours taken, cohort size, age, marital status, employment status, presence of children, weekly exercise, doctor referral for anxiety/stress while in graduate school, medication prescribed for anxiety/depression, type of program (online vs. on campus) and frequency of meeting with an advisor. A point-biserial correlation was automatically conducted by SPSS if the variables were dichotomous. The correlations were conducted using an alpha of .05 to determine what factors are related to the overall stress score of the participants.

\section{Results}

Overall Stress Level. As measured by the Academic Stress Scale, 44\% (N=105), of SLP GS fell into the high stress level range, 52\% ( $\mathrm{N}=123)$ of SLP GS fell into the moderate stress level range, and $4 \%(\mathrm{~N}=10)$ of SLP GS were in the low stress level range.

The frequencies, percentages of responses for the demographic and program characteristics of the participants are summarized in Table 1. The range of credit hours taken in the students' current semesters was $1-21$ credit hours, with 11.18 as the mean number of credit hours taken in a given semester.

Types of Stressors. Participants most frequently rated examinations, tuition costs, and time management as causing "extreme stress" on the Academic Stress Scale. Grades, papers, and studying most frequently elicited the "moderate stress" response from participants. Boring lectures, fast-pace classes, and class speaking most frequently elicited the "hardly stress" response. Finally, uncomfortable classrooms, boring classes, and arriving late most frequently elicited the "no stress" response from participants. 
Demographic and Program Characteristics Related to the Overall Stress Score. Table 1 shows the demographic and program characteristics of the participants. Table 2 summarizes the correlation results to determine which demographic and program characteristics were significantly related to the Academic Stress Scale overall stress score of the participants. There was a significant correlation between the total stress reported by GS in CSD and the following variables: age, $r$ $(238)=-.17, p<.01$; marital status $r(238)=-.142, p<.05$. Older students and students who were married or living with a partner reported lower stress. There was also a significant correlation between the type of program (online or on campus) and stress levels $r(238)=-.19, p<.01$ as the students in distance learning programs reported lower levels of stress overall.

Table 1

Participant Demographic and Academic Characteristics

\begin{tabular}{|c|c|c|c|}
\hline Demographic Categories & Demographic Variables & $\mathbf{N}$ & $\%$ \\
\hline \multirow[t]{2}{*}{ Sex } & Female & 229 & 96.2 \\
\hline & Male & 9 & 3.8 \\
\hline \multirow[t]{4}{*}{ Age } & $20-29$ & 196 & 82.7 \\
\hline & $30-39$ & 25 & 10.5 \\
\hline & $40-49$ & 15 & 6.3 \\
\hline & $50-59$ & 1 & 0.4 \\
\hline \multirow[t]{6}{*}{ Relationship Status } & Not Married & 135 & 56.7 \\
\hline & Married & 38 & 16 \\
\hline & Single Living with Partner & 46 & 19.3 \\
\hline & In Domestic Union & 7 & 2.9 \\
\hline & Divorced & 10 & 4.2 \\
\hline & Widowed & 2 & 0.8 \\
\hline \multirow[t]{2}{*}{ Children } & Yes & 31 & 13 \\
\hline & No & 207 & 87 \\
\hline \multirow[t]{3}{*}{ Employment Status } & Unemployed & 114 & 47.9 \\
\hline & Full Time & 15 & 6.3 \\
\hline & Part Time & 109 & 45.8 \\
\hline \multirow[t]{3}{*}{ Doctor Referral for Anxiety/Stress while in GS } & Yes, After Program & 57 & 23.9 \\
\hline & No & 136 & 57.1 \\
\hline & Yes, Before Program & 22 & 19.2 \\
\hline \multirow[t]{3}{*}{ Medication for Mental Health } & Yes, After Program & 37 & 15.5 \\
\hline & No & 160 & 67.2 \\
\hline & Yes, Before Program & 18 & 7.6 \\
\hline \multirow[t]{3}{*}{ Type of Program } & On Campus & 189 & 79.4 \\
\hline & Online & 30 & 12.6 \\
\hline & Hybrid & 19 & 8 \\
\hline \multirow[t]{4}{*}{ Year of Study } & First Year & 73 & 30.7 \\
\hline & Second Year & 148 & 62.2 \\
\hline & Third Year & 14 & 5.9 \\
\hline & Fourth Plus & 3 & 1.2 \\
\hline Meeting with Advisor & $1-2$ times per week & 81 & 34 \\
\hline
\end{tabular}




\begin{tabular}{|l|l|l|l|}
\hline & $1-2$ times per month & 28 & 11.8 \\
\hline & $1-2$ times per semester & 63 & 26.5 \\
\hline & $1-2$ times per year & 25 & 10.5 \\
\hline & Never met with advisor & 41 & 17.2 \\
\hline
\end{tabular}

Table 2

Correlations for Total GS Stress Scores and Demographic/Program Factors

\begin{tabular}{|c|c|c|c|c|c|c|c|c|c|c|c|c|c|}
\hline & 1 & 2 & 3 & 4 & 5 & 6 & 7 & 8 & 9 & 10 & 11 & 12 & 13 \\
\hline Total Stress & 1 & & & & & & & & & & & & \\
\hline Age & $.17^{* * *}$ & 1 & & & & & & & & & & & \\
\hline Credit Hours & .10 & $-.26^{* *}$ & 1 & & & & & & & & & & \\
\hline Marital Status & $-.14 *$ & $.60 *$ & $-.29 * *$ & 1 & & & & & & & & & \\
\hline Employed & -.03 & .01 & $-.16^{*}$ & .06 & 1 & & & & & & & & \\
\hline Children & -.10 & $.49 * *$ & $-.18 * *$ & $.49 * *$ & -.04 & 1 & & & & & & & \\
\hline Exercise & -.09 & .07 & -.15 & -.04 & $.14^{*}$ & -.04 & 1 & & & & & & \\
\hline $\begin{array}{l}\text { Doctoral } \\
\text { Referral }\end{array}$ & -.22 & .03 & .06 & -.10 & -.01 & -.02 & .01 & 1 & & & & & \\
\hline Medication & -.11 & .01 & .16 & -.06 & -.01 & -.00 & -.00 & $-.53 * *$ & 1 & & & & \\
\hline Meet Advisor & .09 & $-.33 * *$ & $.14 *$ & $-.25 * *$ & -.04 & $-.21 * *$ & .08 & .05 & -.01 & 1 & & & \\
\hline $\begin{array}{l}\text { Program } \\
\text { Type }\end{array}$ & $-.19 * *$ & $.40 * *$ & $.38^{* *}$ & $.33 * *$ & $.28^{* *}$ & $-.30 * *$ & .13 & .04 & .11 & $-.28 * *$ & 1 & & \\
\hline Cohort Size & .10 & $.14 *$ & $-.22 * *$ & .09 & .11 & .05 & .02 & .08 & .12 & -.06 & $.29 * *$ & 1 & \\
\hline Year of Study & -.06 & .13 & $-.28 * *$ & $-.14^{*}$ & $-.13 *$ & -.01 & -.06 & $-.16^{*}$ & -.05 & -.09 & .06 & -.03 & 1 \\
\hline
\end{tabular}

$* \mathrm{p} \leq 0.05 * * \mathrm{p} \leq 0.01$

University Supports Suggested as Potentially Helpful by Respondents. Sixty-five percent $(\mathrm{N}=155)$ of students did not answer the open-ended question or reported not knowing about any university resources to support them with their stress during their program. Other students offered ways in which universities could support them in stress reduction management. The three most commonly suggested ways were: frequent communication with professors and mentors (28\%, $\mathrm{N}=67$ ), increasing student awareness of resources on campus (i.e., counseling services) (20\%, $\mathrm{N}=48$ ), and providing classes/seminars to assist with stress management (i.e., meditation, yoga, time-management, etc.) $(19 \%, \mathrm{~N}=45)$.

\section{Discussion}

The purpose of this study was to investigate the stress levels and types of stressors experienced by SLP GS and to identify academic program supports suggested as potentially helpful. Students who were currently enrolled in a graduate program in SLP completed a survey regarding their demographics, graduate program characteristics, and the levels and types of stress they were experiencing in their academic program. Moderate and high levels of stress were reported by $96 \%$ of SLP GS as measured by the Academic Stress Scale. The most common sources of extreme stress were exams, tuition costs, and managing time. Lower levels of reported total stress experienced by GS in CSD were correlated with increased age and married or cohabitating with a partner and distance learning. In regard to what academic programs could do to reduce their students' stress, participants most commonly mentioned frequent communication with faculty, increased communication about stress resources available on campus, and classes/seminars to help students manage stress. 
Gender and Stress. Although the field of SLP has pushed for diversity in those pursuing degrees in SLP, students studying SLP tend to be women (Rowden-Racette, 2013). This study was consistent with these previous data as only nine males participated in this study $(\mathrm{N}=9)$, preventing any meaningful analyses of gender differences. Additionally, the survey provided only a binary choice for gender. The survey may have not represented individuals who are gender nonconforming. However, due to the large number of women who responded to the survey $(\mathrm{N}=229)$ and results of previous research supporting a gender difference in students' stress response, a discussion of the potential differences in the stress response of male and female SLP students may be beneficial. Fields such as medicine (Bore et al., 2016), dentistry (Crego, Carrillo-Diaz, Armfield, \& Romero, 2016), and other allied health fields (Daisuke \& Ayumi, 2016; Hamaideh \& Hamdan-Mansour, 2014) have noted gender differences in the stress levels of their students. Women, in general, tend to report higher stress levels and a larger incidence of stress related health conditions in comparison to their male counterparts (Tingey, Kiger, \& Riley, 1996; Anthony et al., 2005; Giuseffi et al., 2011). However, when stressed, men are less likely to seek out help, especially for emotional and depressive issues (Möller-Leimkühler, 2002). This higher incidence of stress and stress related disorders in women may largely be due to the multiple roles at home and at school women often manage and the increased likelihood that women may struggle financially (Matud, 2004). According to the National Institute of Mental Health (NIMH) (2001), women are twice as likely to have a clinical diagnosis of depression compared to men. Women, in comparison to men, also tend to report that money is a significant stressor (APA, 2010).

Age and Stress. Internally and physically, young adults undergo a great deal of change. Family and socioeconomic roles are often shifted, and young adults may find themselves responsible for things that were previously in the hands of their parents such as managing finances, arranging medical appointments, etc. (Bonnie, Stroud, \& Breiner, 2015). In the present study, younger students reported higher levels of stress compared to their older counterparts. Although older students may be balancing multiple roles (family and work responsibilities), it appears that younger students actually find their academic experiences more stressful. The 2011 Stress in America Survey conducted by the APA reported that the millennial generation has the highest stress levels of any generation studied. Stress of millennial students were mostly related to worries about finances and the economy (APA, 2011). Younger GS in SLP reported stress levels similar to the millennial respondents in the APA study with worries about finances being a priority concern for the SLP graduate respondents as well. Barring millennials, as individual's age, they report better planning and use of stress management techniques (Giuseffi et al., 2011) and thus may be less stressed about academic experiences as found in this study.

Type of Program and Stress. Students enrolled in distance learning programs reported lower stress levels compared with students enrolled in traditional on-campus programs. Despite the fact that students in distance programs have reported stressors such as frustration from feelings of isolation, lack of immediacy in responses, and technical problems (Song, Singleton, Hill, \& Koh, 2004), distance learning students in the present study reported overall lower levels of stress. This may be due to the fact that many academic programs have made adjustments to enhance the online learner experience (Kuzma, Kuzma, \& Thiewes, 2015). Previous research has also identified other potential reasons that online students may report less stress than on-campus students. First, the flexibility of online programs may afford students the options of attending classes and 
completing assignments on their own schedule, thus reducing stress levels. Also, many students who are enrolled in online programs also work. Working may reduce the financial burden felt by online students and, thus, their stress levels would be lower. Finally, the relationship observed between type of program and reported stress levels may actually be more related to the fact that students in online programs tend to be non-traditional, older students. Therefore, the relationship noted may be less to do with type of program and more to do with the factor of age in relationship to stress.

Academic Program and Stress. There may be several reasons why the results did not provide evidence of a relationship between program characteristics (size of cohort, number of credit hours taken, and frequency of advisor meetings). First, students may react to the stress in unique and individual ways based on their perception of the demands and their capacity to meet those demands (McVicar, 2003). Thus, the same stressor may have an adverse reaction on one person and a neutral reaction on another person.

As previously stated, the students who participated in this research noted several ways in which their academic programs may support them in stress management. Some of the suggestions included time management classes/resources and stress reduction classes/resources. Several researchers have demonstrated a relationship between effective time management skills and stress levels (Campbell \& Svenson, 1992; Lay \& Schouwenburg, 1993). Specifically, Misra and McKean (2000) found that providing students with time management skills helped them lower academic stress.

Additionally, $28 \%$ of the GS responding to the survey stated that they would recommend more frequent communication from faculty as a support to their stress management. This suggestion stands in contrast to the finding that more frequent advisor meetings was not related to a lower stress score. Perhaps it is not necessarily the number of advisor meetings that help a student cope with stress, but instead, it is the quality of those meetings or the relationship with the advisor. Researchers have noted that high levels of purposeful student-faculty contact and institutional environments perceived by students as inclusive are important for student success (Astin 1991; Chickering \& Gamson 1987; Chickering \& Reisser 1993; Kuh et al., 1991). Further, when expectations for performance are openly communicated students are often more successful (Pascarella 1980; Pascarella \& Terenzini 1991, 2005).

Another frequent suggestion was for academic programs to encourage stress reduction by hosting yoga and mind-body skills sessions for students. Mind-body skills groups have been offered in some medical programs across the country in efforts to help medical students develop stressreduction techniques and gain exposure to mind-body medicine while in medical school (Saunders et al., 2007). Mind-body skills include the practices of meditation, mindfulness, and movement and the benefits of mind-body groups for medical students have been widely noted (Saunders et al., 2007). For example, Saunders et al. (2007) discovered that first year medical students participating in a university-led, eleven-week mind-body group reported self-discovery and stress relief following the program. Their findings also emphasized that the mind-body skills program allowed for opportunities for students to make connection with others who were going through a similar experience. Deckro and colleagues (2002) reported similar results for college students attending a six-week mind-body skills program. Specifically, they found that students gained 
stress management skills and reported a reduction in psychological distress and anxiety. Additionally, yoga and mindfulness has been studied in SLP and found to be effective in reducing students' perception of their stress and increasing management of their stress (Beck \& Verticcho, 2014; Beck et al., 2015; Beck et al., 2017). Based on these findings, SLP academic programs may want to consider hosting mind-body skills sessions for their GS in an effort to help students manage stress and learn information about mind-body medicine that can benefit themselves and possibly their future clients.

Finally, other allied health fields, such as physical therapy (Daisuke \& Ayumi, 2016) and medicine, respiratory therapy, pharmacy, and nursing (Hamaideh \& Hamdan-Mansour, 2014) are investigating factors that affect stress, such as coping strategies and psychological, cognitive, and personal variables that impact academic achievement (Daisuke \& Ayumi, 2016; Hamaideh \& Hamdan-Mansour, 2014). The role of sources of stress and coping strategies in relation to the wellbeing of nursing students who were in their final year of study was found to be moderated by improving how students view support and students' belief in their ability to succeed (Gibbons, Dempster, \& Moutray, 2011).

Limitations and Future Research. There are several limitations of this study and potential future research in this area. First, an increase in the numbers of responses would allow more generalization. Also, an increase in respondents could yield more male participants which would allow for an analysis of differences in the stress response of males and females. Not all factors that contribute to individuals' stress response could be measured in this survey. For example, external relationship supports, diet, and previous history of trauma are a few of many examples of things that were not measured on the current survey but may have impacted the respondents' reported stress levels. Additionally, future research is needed in regard to the implementation of program support for student stress. For instance, it would be useful to investigate whether university programs related to time and stress management may impact a student's reported stress. Also, because Beck and colleagues (2017) found that graduate students studying speech-languagepathology benefitted from 20-minute mindfulness practice sessions, further exploration of how mindfulness and/or mind-body skill sessions may impact students who report high levels of stress would be worthwhile. Given the fact that many students were unaware of existing program supports, it may be beneficial to implement an awareness campaign for these program supports and examine the effects on students' participation in the available programs.

\section{References}

Adsett, C. A. (1968). Psychological health of medical students in relation to the medical education process. Journal of Medical Education, 43, 728-734.

American Psychological Association (2010). Stress in America: Our health at risk [PDF]. Retrieved from https://www.apa.org/news/press/releases/stress/2010/national-report.pdf

American Psychological Association (2011). Stress in America: Our health at risk [PDF]. Retrieved from https://www.apa.org/news/press/releases/stress/2011/final-2011.pdf

American Speech-Language-Hearing Association. (2016). Scope of practice in speech-language pathology [Scope of Practice]. Available from www.asha.org/policy/.

Anthony, L. G., Anthony, B. J., Glanville, D. N., Naiman, D. Q., Waanders, C., \& Shaffer, S. (2005). The relationships between parenting stress, parenting behaviour and preschoolers' 
social competence and behaviour problems in the classroom. Infant and Child Development, 14(2), 133-154.

Astin, A. W. (1991). The changing American college student: Implications for educational policy and practice. Higher Education, 22(2): 129-143.

Bangasser, D. A., \& Wicks, B. (2017). Sex-specific mechanisms for responding to stress. Journal of Neuroscience Research, 95(1-2), 75-82.

Beck, A. R., \& Verticchio, H. (2014). Facilitating speech-language pathology graduate students' ability to manage stress: A pilot study. Contemporary Issues in Communication Science and Disorders, 41, 24-38.

Beck, A. R., Seeman, S., Verticchio, H., \& Rice, J. (2015). Yoga as a technique to reduce stress experienced by CSD graduate students. Contemporary Issues in Communication Science and Disorders, 42, 1-15.

Beck, A. R., Verticchio, H., Seeman, S., Milliken, E., \& Schaab, H. (2017). A mindfulness practice for communication sciences and disorders undergraduate and speech-language pathology graduate students: Effects on stress, self-compassion, and perfectionism. American Journal of Speech-Language Pathology, 26(3), 893-907.

Benton, S. A., Robertson, J. M., Wen-Chih, T., Newton, F. B., \& Benton, S. L. (2003). Changes in counseling center client problems across 13 years. Professional Psychology-Research and Practice, 34, 66-72.

Bland, H. W., Melton, B. F., Welle, P., \& Bigham, L. (2012). Stress tolerance: New challenges for millennial college students. College Student Journal, 46(2), 362 - 376.

Bonnie, R. J., Stroud, S., Breiner, H. (2015). Investing in the health and well-being of young adults. Washington D.C.: The National Academic Press.

Bore, M., Kelly, B., \& Nair, B. (2016). Potential predictors of psychological distress and wellbeing in medical students: A cross-sectional pilot study. Advances in Medical Education and Practice, 7, 125-135.

Butler, A. B., Dodge, K. D., \& Faurote, E. J. (2010). College student employment and drinking: A daily study of work stressors, alcohol expectancies, and alcohol consumption. Journal of Occupational Health Psychology, 15(3), 291.

Calkins, E. V., Arnold, L., \& Willoughby, T. L. (1994). Medical students' perceptions of stress: Gender and ethnic considerations. Academic Medicine, 69(10), S22-4.

Campbell, R. L, \& Svenson, L. W. (1992). Perceived level of stress among university undergraduate students in Edmonton, Canada. Perceptual and Motor Skills, 75(2), 552554.

Carver, C. S. (1997). You want to measure coping but your protocol's too long: Consider the Brief COPE. International Journal of Behavioral Medicine, 4, 92-100.

Center for Collegiate Mental Health. (2014). 2013 Annual report (Publication No. STA 14-43) [PDF]. Retrieved from https://sites.psu.edu/ccmh/files/2017/10/2013_CCMH_Report12evq763.pdf

Chickering, A. W., \& Gamson, Z. F. (1987). Seven principles for good practice in undergraduate education. American Association for Higher Education, 3, 7.

Chickering, A. W., \& Reisser, L. (1993). Education and Identity. San Francisco, CA: The JosseyBass Higher and Adult Education Series.

Crary, P. (2013). Beliefs, behaviors, and health of undergraduate nursing students. Holistic Nursing Practice, 27(2), 74-88. 
Crego, A., Carrillo-Diaz, M., Armfield, J.M. and Romero, M. (2016) Stress and academic performance in dental students: The role of coping strategies and examination-related selfefficacy. Journal of Dental Education, 80, 165-172.

Daisuke, H., \& Ayumi, E. (2016) Characteristics of coping strategies and the relationships between coping strategies and stress reactions in physical therapy students during clinical practice. Journal of Physical Therapy Science, 10, 2867-2870.

Deckro, G. R., Ballinger, K. M., Hoyt, M., Wilcher, M., Dusek, J., Myers, P., Greenberg, B., Rosenthal, D. S. \& Benson, H. (2002). The evaluation of a mind/body intervention to reduce psychological distress and perceived stress in college students. Journal of American College Health, 50(6), 281-287.

Donner, N. C., \& Lowry, C. A. (2013). Sex differences in anxiety and emotional behavior. Pflugers Archiv -European Journal of Physiology, 465(5), 601-626.

Ellis, B. J., Jackson, J. J., \& Boyce, W. T. (2006). The stress response systems: Universality and adaptive individual differences. Developmental Review, 26, 175-212.

Flanning, G. G. (2016). Academic stress and academic self-efficacy as predictors of psychological health in college students (Doctoral dissertation). Retrieved from ProQuest. (10294625)

Garett, R., Liu, S., \& Young, S. D. (2017). A longitudinal analysis of stress among incoming college freshmen. Journal of American College Health, 1-8.

Gibbons, C., Dempster, M., \& Moutray, M. (2011). Stress, coping and satisfaction in nursing students. Journal of Advanced Nursing, 67(3), 621-632.

Giuseffi, D. L., Bedrosian, R. C., Schwartz, S. M., Wildenhaus, K. J., Wang, C., Yu, A., \& Wiegand, B. (2011). Women using a web-based digital health coaching programme for stress management: Stress sources, symptoms and coping strategies. Stress and Health, 27(3), e269-e281.

Gordan, J. (2014). Mind-body skills groups for medical students: Reducing stress, enhancing commitment, and promoting patient-centered care. BioMed Central Medical Education, 14, 198.

Hamaideh, S. H., \& Hamdan-Mansour, A. M. (2014). Psychological, cognitive, and personal variables that predict college academic achievement among health sciences students. Nurse Education Today, 34(5), 703-708.

Hunt, J., \& Eisenberg, D. (2010). Mental health problems and help-seeking behavior among college students. Journal of Adolescent Health, 46, 3-10.

Hyun, J. K., Quinn, B. C., Madon, T., \& Lustig, S. (2006). Graduate student mental health: Needs assessment and utilization of counseling services. Journal of College Student Development, 47(3), 247-266.

IBM Corp. (2016). IBM SPSS Statistics for Windows (Version 24.0) [Computer software]. Armonk, NY: IBM Corp.

Kilpatrick, L. A., Istrin, J. J., Gupta, A., Naliboff, B. D., Tillisch, K., Labus, J. S., \& Mayer, E. A. (2015). Sex commonalities and differences in the relationship between resilient personality and the intrinsic connectivity of the salience and default mode networks. Biological Psychology, 112, 107-115.

Kohn, J. P., \& Frazer, G. H. (1986). An academic stress scale: Identification and rated importance of academic stressors. Psychological Reports, 59, 415-426.

Kuh, G. D., Schuh, J. H., Whitt, E. J., Andreas, R., Lyons, J., Strange, C. C., Krehbiel, L. E., \& MacKay, K. A. (1991). Involving colleges: Successful approaches to fostering student 
learning and development outside the classroom. San Francisco, CA: Jossey-Bass Publishers.

Kuzma, A., Kuzma, J., \& Thiewes, H. (2015). Business student attitudes, experience, and satisfaction with online courses. American Journal of Business Education (Online), 8(2), 121.

Landow, M.V. (2006). Stress and Mental Health of College Students. New York, NY: Nova Science Publishers.

Lay, C. H., \& Schouwenburg, H. C. (1993). Trait procrastination, time management, and academic behavior. Journal of Social Behavior \& Personality, 84(4), 647-662.

Lo, R. (2002). A longitudinal study of perceived level of stress, coping and self-esteem of undergraduate nursing students: An Australian case study. Journal of Advanced Nursing, 39(2), 119-126.

Marques, A. A., Bevilaqua, M. C., da Fonseca, A. M., Nardi, A. E., Thuret, S. \& Dias, G. P. (2016). Gender differences in the neurobiology of anxiety: Focus on adult hippocampal neurogenesis, Neural Plasticity, 1-14.

Matud, M. P. (2004). Gender differences in stress and coping styles. Personality and Individual Differences, 37, (7), 1401-1415.

McLaughlin, M. (1985). Graduate schools and families: Issues for academic departments and university mental health professions. Journal of College Student Personnel, 26, 488-491.

McVicar, A. (2003). Workplace stress in nursing: A literature review. Journal of Advanced Nursing, 44(6), 633-642.

Mese, J., \& Spano, C. (1989, May). Retention through intervention: A strategic plan for retention of high-risk students. Miami-Dade Community College, Florida Medical Center Campus.

Misra, R., \& McKean, M. (2000). College students' academic stress and its relation to their anxiety, time management, and leisure satisfaction. American Journal of Health Studies, 16(1), 4151.

Moffat, K. J., McConnachie, A., Ross, S., \& Morrison, J. M. (2004). First year medical student stress and coping in a problem-based learning medical curriculum. Medical education, 38(5), 482-491.

Möller-Leimkühler, A. M. (2002). Barriers to help-seeking by men: A review of sociocultural and clinical literature with particular reference to depression. Journal of Affective Disorders, 71(1), 1-9.

National Institute of Mental Health. (2001). Women hold up half the sky: Women and mental health research. National Institute of Mental Health, National Institutes of Health, US Department of Health and Human Services. (NIH Publication No. 01-4607). Retrieved from https://www.nimh.nih.gov/health/topics/women-and-mental-health/index.shtml

Ngun, T. C., Ghahramani, N., Sánchez, F. J., Bocklandt, S., \& Vilain, E. (2011). The genetics of sex differences in brain and behavior. Frontiers in Neuroendocrinology, 32, 227-246.

Papazisis, G., Tsiga, E., Papanikolaou, N., Vlasiadis, I., \& Sapountzi-Krepia, D. (2008). Psychological distress, anxiety and depression among nursing students in Greece. International Journal of Caring Sciences, 1(1), 42.

Pascarella, E. T. (1980). Student-faculty informal contact and college outcomes. Review of Educational Research, 50(4), 545-595.

Pascarella, E. T. \& Terenzini, P. T. (1991). How college affects students: Findings and insights from twenty-years of research (1st ed.). San Francisco, CA: Jossey-Bass Publishers. 
Pascarella, E .T. \& Terenzini, P. T. (2005). How college affects students: A third decade of research. San Francisco, CA: Jossey-Bass Publishers.

Peters, R. (1997) Getting what you came for: The smart students guide to earning a master's or Ph.D. New York, NY: Farrar, Straus, and Garraut.

Pryor, J. H., Hurtado, S., DeAngelo, L., Palucki Blake, L., \& Tran, S. (2010). The American Freshman: National Norms Fall 2010. Los Angeles, CA: Higher Education Research Institute, UCLA.

Riggert, S. C., Boyle, M., Petrosko, J. M., Ash, D., \& Rude-Parkins, C. (2006). Student employment and higher education: Empiricism and contradiction. Review of Educational Research, 76(1), 63-73, 75-92.

Ross, S. E., Niebling, B. C., \& Heckert, T. M. (1999). Sources of stress among college students. College Student Journal, 33, 312-318.

Rowden-Racette, K. (2013). Where the boys aren't: What do we know about the barriers to gender parity in CSD and is there anything more that can be done? ASHA Leader, 18, 46-51.

Saunders, P.A., Tractenberg, R. E., Chaterji, R., Amri, H., Harazduk, N., Gordon, J.S., Lumpkin, M., \& Haramati, A. (2007). Promoting self-awareness and reflection through an experiential mind-body skills course for first year medical students. Medical Teacher, 29 (8), 778-784.

Seo, D., Ahluwalia, A., Potenza, M. N., \& Sinha, R. (2017). Gender differences in neural correlates of stress-induced anxiety. Journal of Neuroscience Research, 95(1-2), 115-125.

Smith, T., \& Renk, K. (2007). Predictors of academic-related stress in college students: An examination of coping, social support, parenting, and anxiety. NASPA Journal, 44(3), 405431.

Song, L., Singleton, E. S., Hill, J. R., \& Koh, M. H. (2004). Improving online learning: Student perceptions of useful and challenging characteristics. The Internet and Higher Education, 7(1), 59-70.

Tingey, H., Kiger, G., \& Riley, P. J. (1996). Juggling multiple roles: Perceptions of working mothers. The Social Science Journal, 33, 183-191.

Towbes, L. C., \& Cohen, L. H. (1996). Chronic stress in the lives of college students: Scale development and prospective prediction of distress. Journal of Youth and Adolescence, 25, 199-217.

Turner, A., \& Berry, T. R., (2000). Counseling center contributions to student retention and graduation: A longitudinal assessment. Journal of College Student Development, 41(6), 627-635.

Walsh, J. M., Feeney, C., Hussey, J., \& Donnellan, C. (2010). Sources of stress and psychological morbidity among undergraduate physiotherapy students. Physiotherapy, 96(3), 206-212.

Wilks, S. E. (2008). Resilience amid academic stress: The moderating impact of social support among social work students. Advances in Social Work, 9(2), 106-125.

Wilson, S. B., Mason, T. W., \& Ewing, M. J. M. (1997). Evaluating the impact of receiving university-based counseling services on student retention. Journal of Counseling Psychology, 44, 316-320. 